\title{
AUSCULTATORY AND PHONOCARDIOGRAPHIC SIGNS OF ATRIAL SEPTAL DEFECT
}

\author{
BY \\ AUBREY LEATHAM AND IAN GRAY \\ From the Institute of Cardiology, National Heart Hospital \\ Received October 4, 1955
}

Atrial septal defect from persistence of the ostium secundum, or occasionally of the ostium primum, is one of the most common varieties of congenital heart disease. The clinical signs in previously published cases were evaluated by Roesler (1934), and clarified in a large personal series by Bedford et al. (1941). At that time the frequency of a systolic murmur was well recognized: it had been attributed by Roesler (1934) to associated mitral valve disease, and by Taussig et al. (1938) to interatrial flow. Diastolic murmurs were ascribed to mitral valve disease or to pulmonary incompetence. The pulmonary second sound was described as accentuated. The diagnosis rested mainly on the radiological findings first described by Assman (1929), and the electrocardiogram (Routier et al., 1940). Physical examination, except for the evidence of right heart involvement, was thought to offer little or no assistance in the diagnosis of atrial septal defect (Burrett and White, 1945). Cardiac catheterization enabled the diagnosis to be made at an earlier stage (Brannon et al., 1945) and the physical signs were re-examined by Barber et al. (1950), and by Wood (1950) who pointed out that the second sound was split and not accentuated in uncomplicated atrial septal defect. They found a diastolic murmur at the left sternal edge in half their cases and attributed this to pulmonary incompetence. The development of the phonocardiograph has allowed a more accurate analysis of the heart sounds and murmurs in atrial septal defect. This shows that auscultation can be an important aid to the clinical diagnosis.

\section{MeTHOD OF INVESTIGATION}

An auscultatory and phonocardiographic investigation was made of 40 consecutive patients in whom the diagnosis of atrial septal defect as the main cardiac abnormality was established by cardiac catheterization. There were three main groups (Table I). In 23 patients it was thought to be uncomplicated and a left-to-right shunt of 3 to 14 litres a minute was found. In 6 of these patients a small pressure gradient

TABLE I

Atrial Septal Defect

\begin{tabular}{ccc|c|c|c}
\hline & & & Catheterized & $\begin{array}{c}\text { Operation } \\
\text { and/or } \\
\text { necropsy }\end{array}$ & Total \\
\hline Uncomplicated & $\ldots$ & $\ldots$ & $\ldots$ & 23 & 3 \\
\hline Additional pulmonary stenosis & $\ldots$ & $\ldots$ & 7 & 1 & 26 \\
\hline With pulmonary hypertension & $\ldots$ & $\ldots$ & 10 & $6 *$ & 16 \\
\hline Total & $\ldots$ & $\ldots$ & 40 & 10 & 50 \\
\hline
\end{tabular}

* 2 with mitral stenosis. 
(less than $15 \mathrm{~mm} . \mathrm{Hg}$ ) was found across the pulmonary valve and was thought to be related to the high flow and dilated pulmonary artery rather than to additional pulmonary stenosis. In a second group of seven cases a pressure gradient of 25 to $50 \mathrm{~mm}$. Hg was found across the pulmonary valve and was attributed to additional pulmonary stenosis-a substantial left-to-right shunt being maintained in all these patients. Patients with severe pulmonary stenosis were not included. In a third group of 10 patients there was pulmonary hypertension (pulmonary artery pressure greater than $50 \mathrm{~mm}$. $\mathrm{Hg}$ ) with raised pulmonary resistance.

An additional 10 patients with atrial septal defect were studied in whom operation or necropsy was performed providing exact anatomical diagnosis particularly in relation to the mitral valve. The mitral valve was specially examined in a further 7 post-mortem cases in whom no investigations had been possible.

Auscultation was carried out in each case and the intensity of every sound and murmur was gradedthe classification of Freeman and Levine (1933) being used for systolic murmurs. Special attention was paid to the second heart sound throughout the respiratory cycle and to the timing of systolic and diastolic murmurs. These signs were correlated with the electrocardiogram, radiogram, and results of cardiac catheterization.

High-frequency phonocardiograms (Leatham, 1952) were taken by one of us in each of the 50 cases,

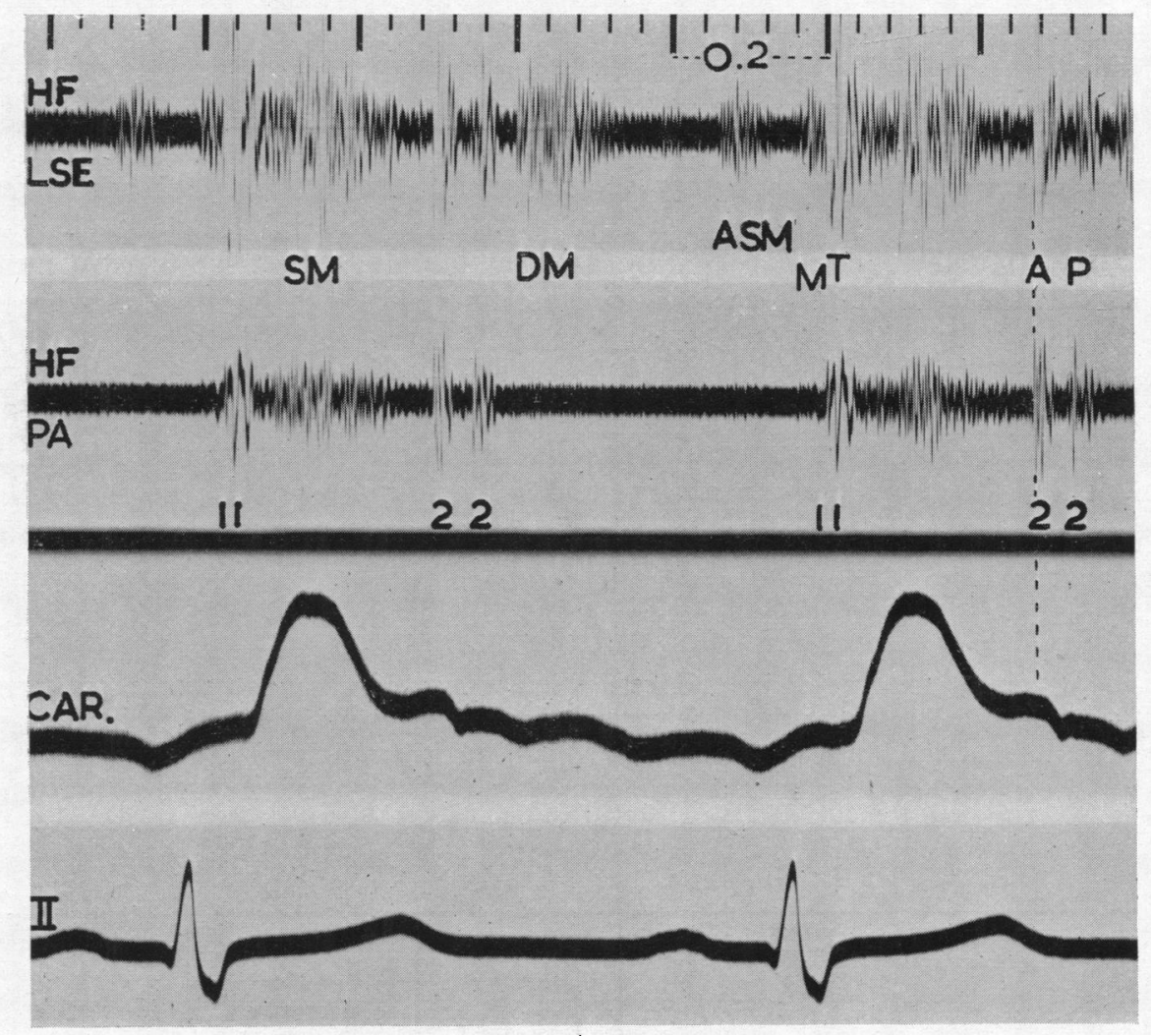

FIG. 1.-Atrial septal defect (PA P. 20/3 mm. Hg. Pulmonary flow $161 . / \mathrm{min}$., systemic 5 1./min.). Simultaneous high-frequency phonocardiograms (HF) from the lower left sternal edge (LSE) and pulmonary area (PA) with indirect carotid pulse (CAR) and electrocardiogram (II). Splitting of first sound with accentuation of second, tricuspid (T), component (coinciding with carotid upstroke-delay $0.04 \mathrm{sec}$.- -and therefore too late for mitral closure). Splitting of second sound with aortic component (A) preceding pulmonary component (P) by $0.06 \mathrm{sec}$. Ejection mid-systolic murmur (SM). Delayed diastolic murmur (DM) beginning $0.05 \mathrm{sec}$. after onset of P2. Right atrial systolic murmur (ASM) $0.08 \mathrm{sec}$. after onset of $P$ wave. Time intervals in this and subsequent records are 0.20 and $0.04 \mathrm{sec}$. 
including the 10 with operative or necropsy control, and were repeated in three after surgical repair. Simultaneous records from different areas with indirect carotid and jugular tracings and electrocardiogram were made in all cases and, in 6, phonocardiograms were recorded at the same time as the pressure pulses during cardiac catheterization. The mitral valve component of the first sound was identified by its dominance at the mitral area and its relation to the upstroke of the carotid pulse, and the tricuspid component by its dominance at the left sternal edge and its relation to the right ventricular pressure pulse. The aortic component of the second sound was identified by its relation to the dicrotic notch of the carotid tracing (Fig. 1), and the pulmonary component from its dominance in the pulmonary area and its relation to the dicrotic notch of the tracing from the pulmonary artery (Fig. 2). The interval from the onset of QRS to the beginning of the upstroke of the right ventricular pressure pulse was measured in all patients, and to the upstroke

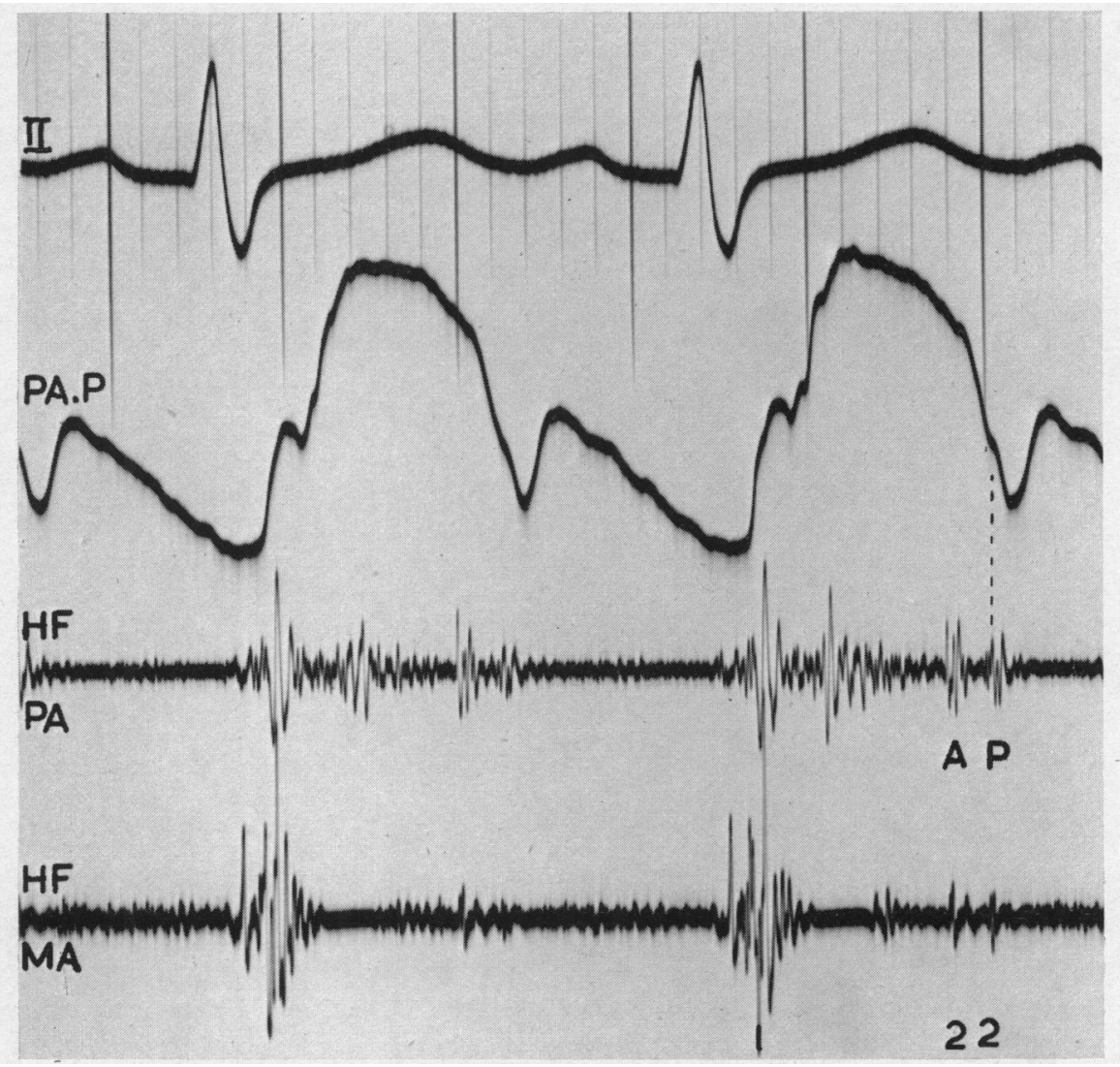

FIG. 2.-Atrial septal defect (same case as Fig. 1). Simultaneous pressure pulse from pulmonary artery (PA P) and phonocardiograms from pulmonary and mitral (MA) areas. The later component of the second sound is shown to be pulmonary by its relation to the dicrotic notch of the PA pulse (delay $0.03 \mathrm{sec}$.).

of the left ventricular pressure pulse in ten, with an allowance of $0.02 \mathrm{sec}$. for delay in the catheter (Leatham and Vogelpoel, 1954). Delay in pulse wave transmission from the aortic valve to the carotid artery was assumed to be given by the time interval from the onset of the aortic component of the second sound to the nadir of the dicrotic notch of the indirect carotid tracing. The duration of right and left ventricular systole was estimated by the time interval between tricuspid and pulmonary, and mitral and aortic valve closures, respectively.

\section{RESUlTS}

First Heart Sound. Splitting of the first sound was recorded in 24 cases yet it was seldom a striking physical sign on auscultation except in the six cases with complete right bundle-branch 
block (Fig. 11). In 18 of the 24 cases in which the phonocardiogram showed splitting, identification of each component was possible and mitral closure invariably preceded tricuspid closure, as in normal subjects (Leatham, 1954). In two patients with complete right bundle-branch block and wide splitting of the first sound in whom pressure pulses were obtained from both ventricles, the first component was proved to be mitral by its synchrony with left ventricular upstroke, and the second to be tricuspid by its synchrony with a delayed right ventricular upstroke. In patients with pulmonary hypertension the first sound was usually single. The first sound was judged to

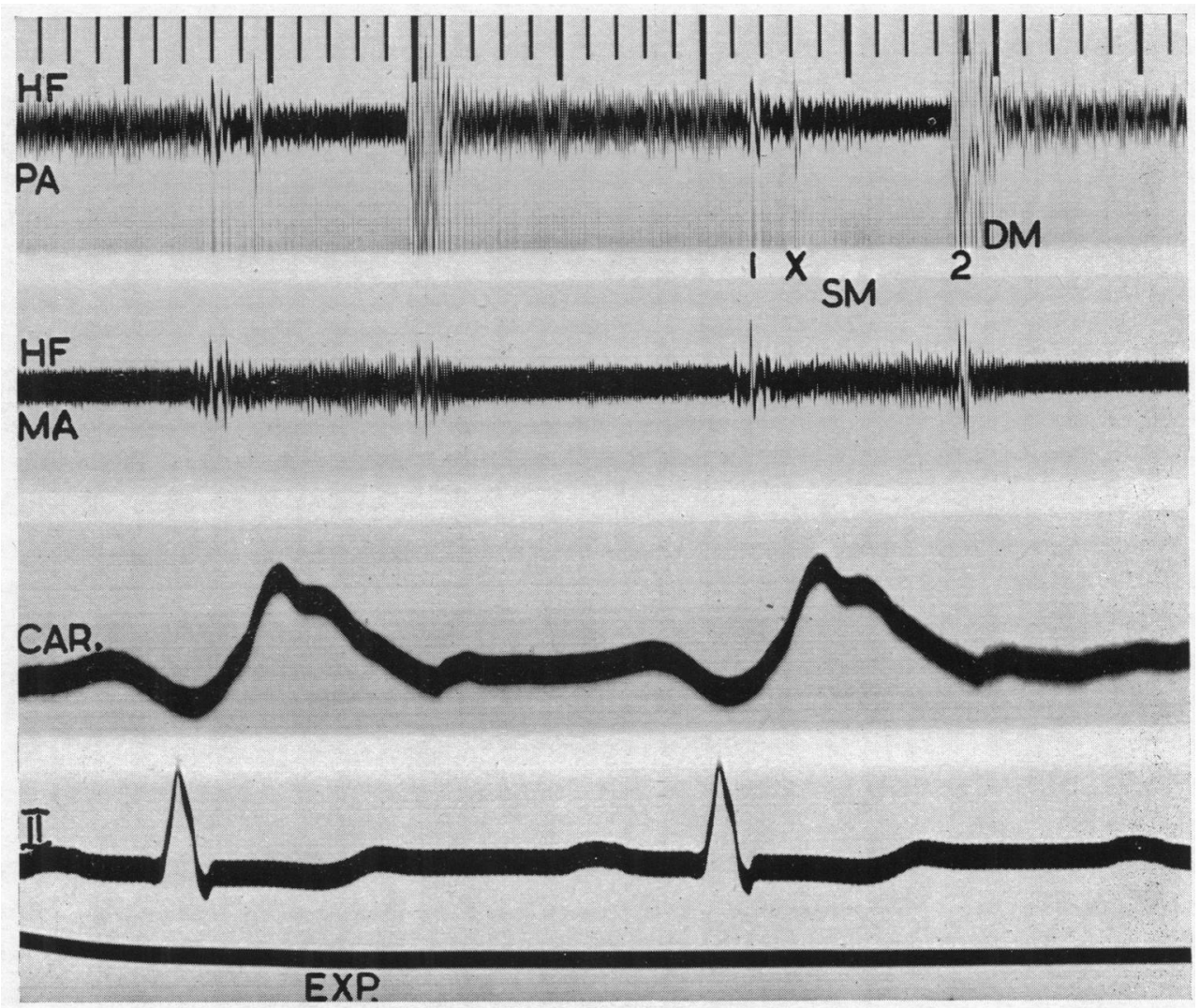

FIG. 3.-Atrial septal defect with pulmonary hypertension (RV P, 135/5 mm. Hg) and reversed shunt. (Pulmonary flow $3.61 . / \mathrm{min}$, systemic flow $4.31 . / \mathrm{min}$.) Ejection sound (X) $0.06 \mathrm{sec}$. after onset of first sound recorded in expiration (EXP.). Large single second sound immediately followed by long early diastolic murmur due to pulmonary incompetence. Pansystolic murmur at mitral area.

be increased in intensity in 17 patients. When the first sound was split in these patients neither component was constantly responsible for the increase in intensity, but in several patients with high rates of pulmonary flow the later tricuspid component was strikingly accentuated (Fig. 1).

A pulmonary early systolic ejection sound was recorded in 15 patients (Fig. 3) and was assoeiated with pulmonary hypertension in 8 , and with additional pulmonary stenosis in 2 . This extra sound was clearly audible in 11 of the 15 patients.

The Second Heart Sound. In healthy subjects the second heart sound in the pulmonary area is single or split by less than $0.03 \mathrm{sec}$. in the expiratory phase of continuous respiration, and becomes more widely split, $0.05 \mathrm{sec}$. or more, during inspiration (Fig. 4). Wide splitting of the second heart sound in the expiratory phase of respiration, without much increase on inspiration, was 


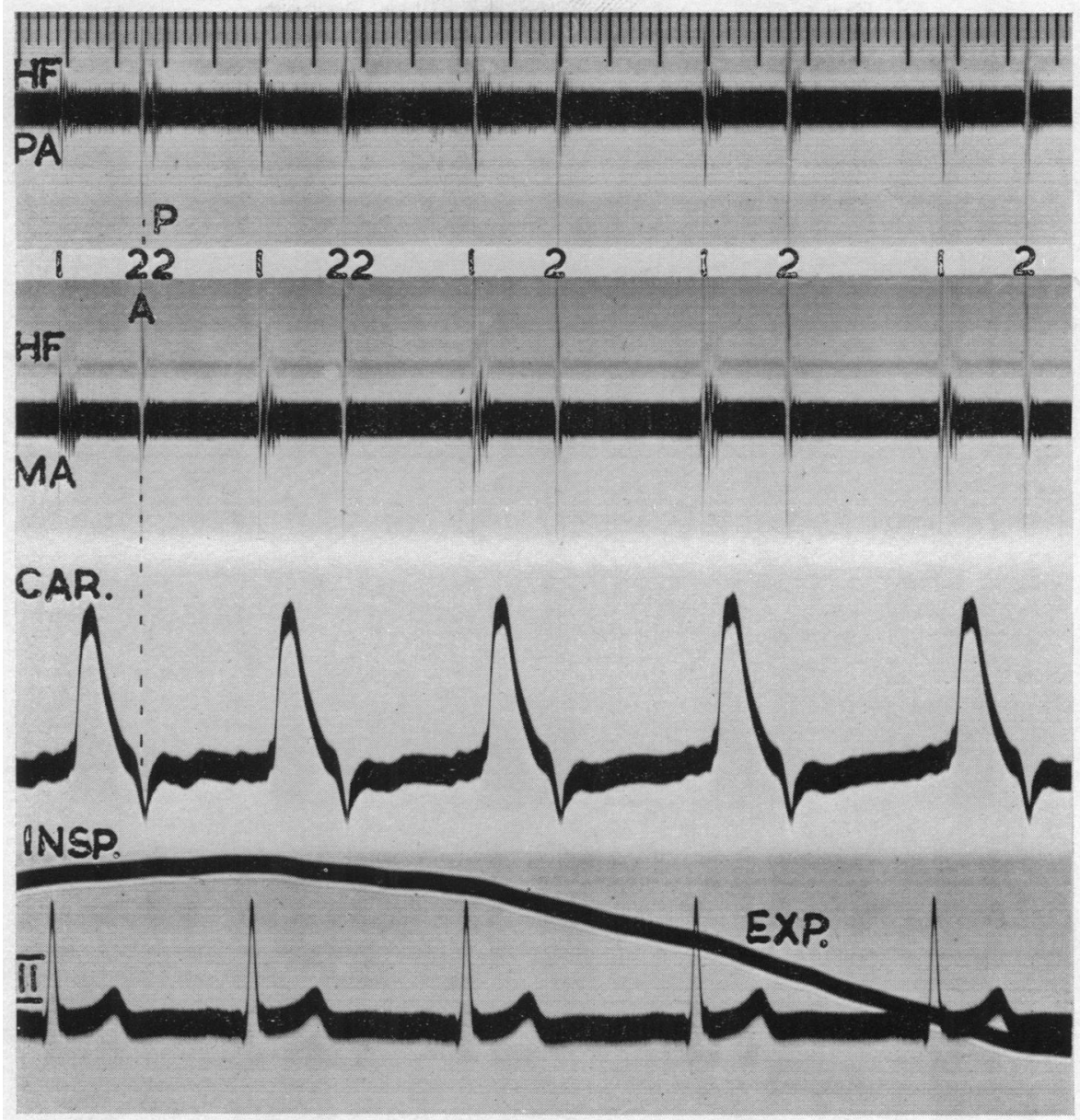

FIG. 4.-Normal subject. During inspiration the second sound in the pulmonary area is split by $0.05 \mathrm{sec}$., and becomes single in the expiratory phase of respiration. The first component is shown to be aortic by its synchrony with the dicrotic notch of the carotid tracing, and the second pulmonary by its localization to the pulmonary area.

recorded in 35 of our cases (Fig. 5) and this abnormality could almost invariably be recognized by auscultation. A satisfactory tracing throughout the respiratory cycle was obtained in 30 cases. There was no change in the width of splitting during inspiration in 21 and in the remaining 9 the split increased by an average of $0.015 \mathrm{sec}$. With synchronous phonocardiograms and carotid tracings it was found that the normal order of events was maintained-aortic valve closure before pulmonary - and that the wide split was due to relative delay in the pulmonary component (Fig. 1 and 2). In 26 cases the split in expiration was 0.03 to $0.05 \mathrm{sec}$.: in 9 cases it was wider, 0.06 to $0 \cdot 10$, and 6 of them were found to have additional pulmonary stenosis. Five of our 40 cases did not show this physical sign of wide and relatively constant splitting of the second heart sound, and in 2 no splitting of the second sound could be heard or recorded (Fig. 3). Both patients had very high pulmonary pressures and resistances with a reversed shunt, and showed the clinical picture of Eisenmenger's syndrome. In the other 3, one of whom had pulmonary hypertension, the splitting was slight, measuring less than $0.03 \mathrm{sec}$. in expiration.

The intensity of the two components of the second sound in the pulmonary area could not be measured directly, but their relative intensity could be compared from their size on the high-frequency 

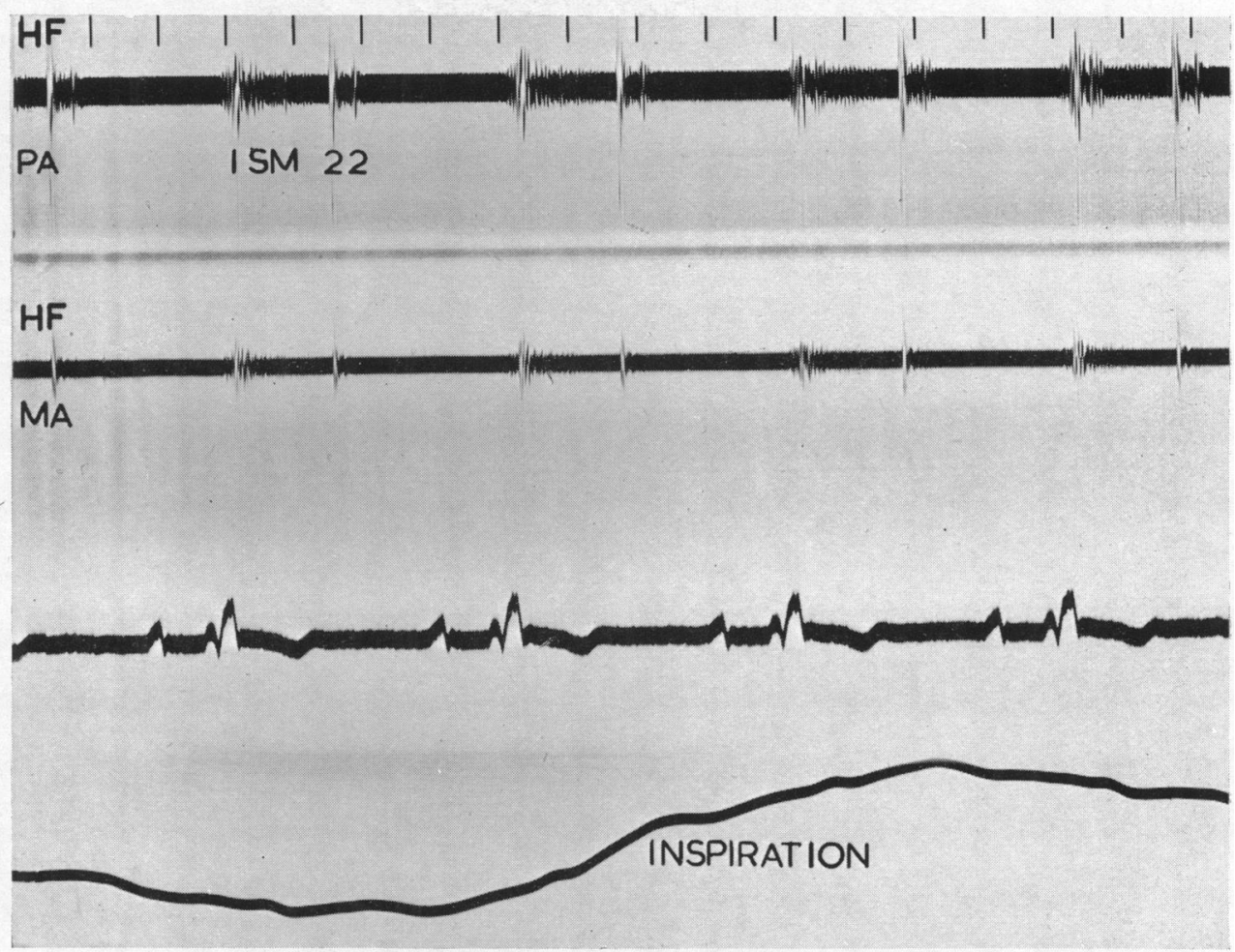

FIG. 5.-Atrial septal defect. Wide splitting of second heart sound remaining unchanged throughout the respiratory cycle.

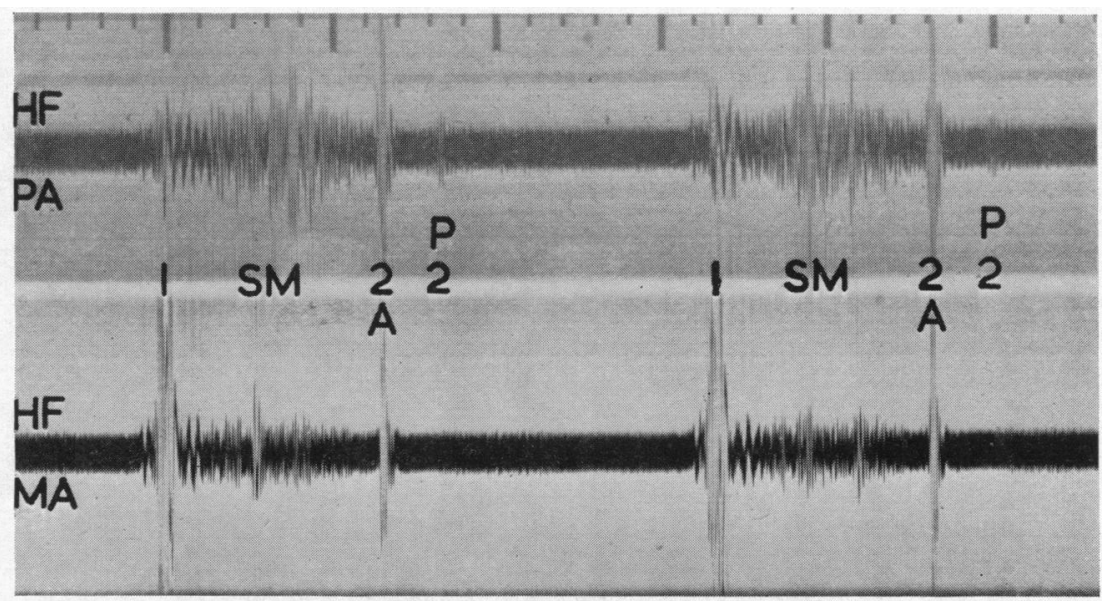

FIG. 6.-Atrial septal defect with pulmonary stenosis (pulmonary flow $191 . / \mathrm{min}$., systemic flow, 7 1./min., PA P, 18/3 mm. Hg, RV P, 48/0 mm. Hg). Pulmonary component of second sound delayed by $0.08 \mathrm{sec}$. and diminished in intensity. 
phonocardiogram. In uncomplicated atrial septal defect the aortic and pulmonary components were about equal and the ratio between them was never greater than two to one (Fig. 1). With additional pulmonary stenosis the intensity of the pulmonary component was diminished in 5 out of 7 cases, the pulmonary component being reduced to as little as one-fifth of the aortic in some (Fig. 6). With pulmonary hypertension (and splitting of the second sound), the pulmonary component was increased in intensity. There was a ratio of 4 to 1 or more in most cases (Fig. 7),

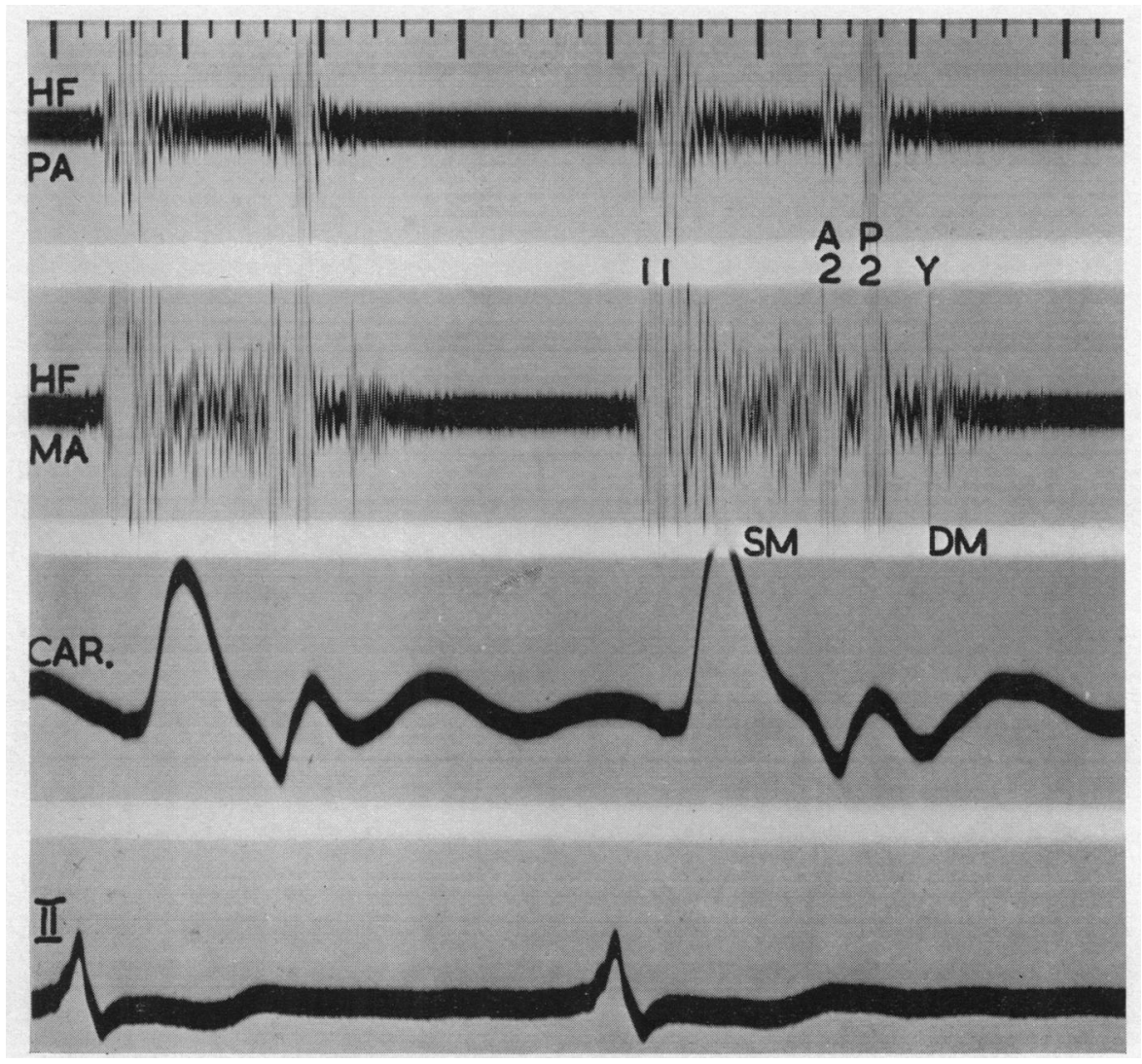

FIG. 7.-Atrial septal defect with pulmonary hypertension (PA P, 85/30 mm. Hg) and tricuspid incompetence, and maintenance of left-to-right shunt. (Pulmonary flow 10.4, systemic flow $4 \cdot 5,1 . / \mathrm{min}$.) Wide splitting of second sound with accentuation of pulmonary component and transmission to mitral area. Early diastolic sound (Y) 0.08 sec. after P2 followed by delayed diastolic murmur. Pulmonary systolic murmur is small. Pansystolic murmur was attributed to tricuspid incompetence. No mitral disease at operation.

but it was within the normal range of 2 to 1 in one. Propagation of the pulmonary component to other areas, making splitting of the second heart sound audible at the apex, is not found in healthy subjects, and usually indicates accentuation of the pulmonary component from pulmonary hypertension (Fig. 7). Splitting of the second sound at the apex was found in all our patients with pulmonary hypertension, except the two with a single second sound in the pulmonary area, but was also present on auscultation in 7 patients with uncomplicated atrial septal defect, and on the phonocardiogram in a further 8 (Fig. 8).

Diastolic Sound. An extra sound in diastole was recorded in 10 patients (Fig. 7) and was 
audible in 4 of them. This sound was high pitched and snapping, maximal at the lower left sternal edge and nearly always of very low intensity and difficult to hear. This extra sound came from 0.03 to 0.08 sec. after the onset of pulmonary valve closure in 8 patients, but in two the interval was longer, measuring $0 \cdot 11$ and $0 \cdot 12 \mathrm{sec}$.

Systolic Murmurs. There was invariably a systolic murmur. In 36 the murmur was best heard at or near the pulmonary area and was shown on the phonocardiogram to be of a distinctive shape which could usually be appreciated clinically. It began soon after the first sound, reaching a maximum in early or mid-systole, and diminished in intensity before the second heart sound. The phonocardiogram showed that this murmur always ended before pulmonary valve closure and

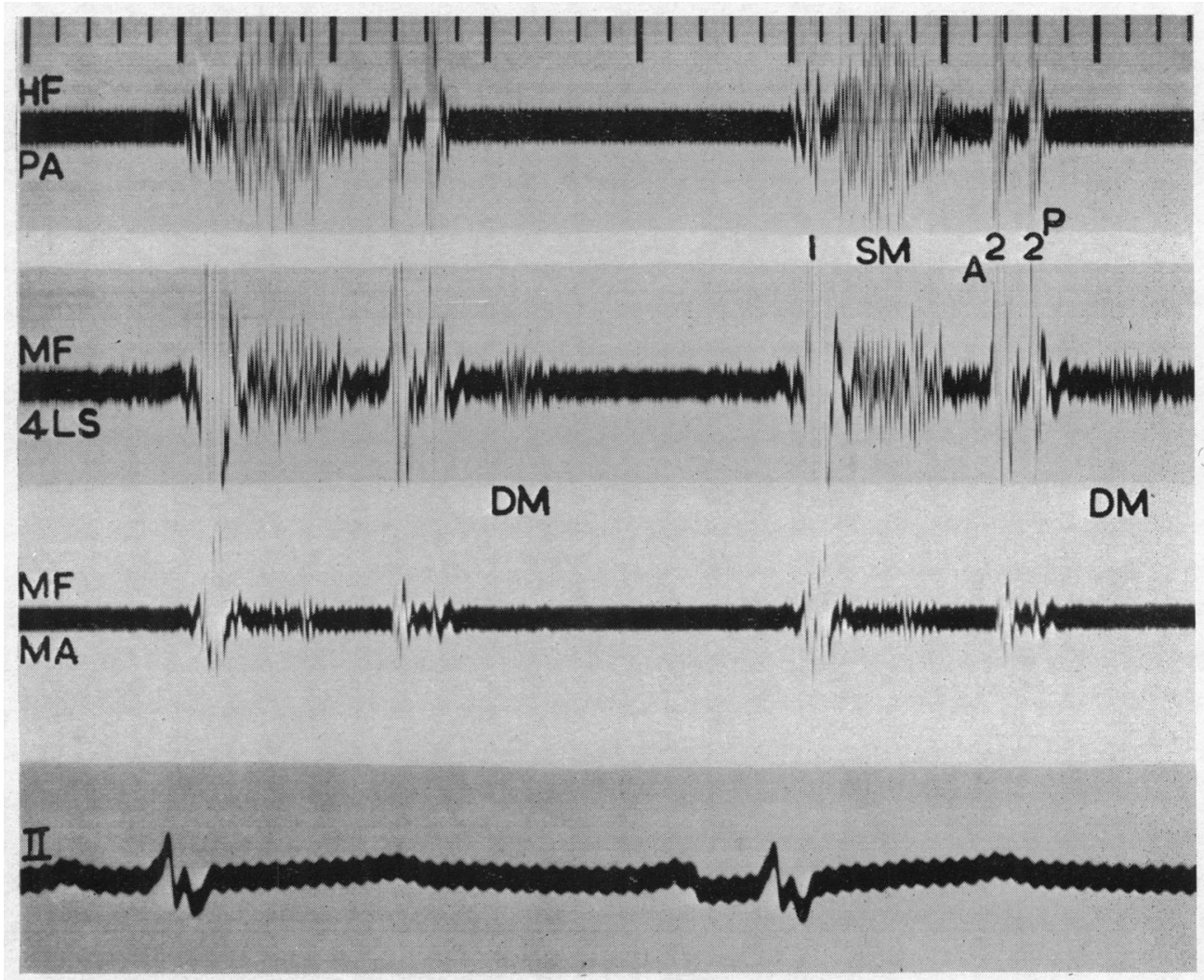

FIG. 8.-Atrial septal defect (pulmonary flow 8, systemic flow 4, 1./min.; PA P, 22/6 mm. Hg). Pulmonary systolic murmur, ending before both components of second sound. P2 transmitted to apex with normal pulmonary pressure. Delayed diastolic murmur shown in medium frequency recording (MF) from the fourth space at the left sternal edge (4 LS).

in uncomplicated atrial septal defect even before the earlier aortic valve closure (Fig. 8); it tended to be slightly longer when there was additional pulmonary stenosis. The pulmonary systolic murmur was loudest in the second left intercostal space in 29 and the third or fourth space in 7 of the 36 cases. In 30 a murmur of the same pattern was heard and recorded at the apex and was thought to have been transmitted from the pulmonary area (Fig. 9). The murmur was moderately loud (grade 3 or 4 ) in 20 and soft (grade 1 or 2) in 9 cases. In 7 the murmur was louder (grade 5) and was accompanied by a thrill, and in four of these catheterization showed additional pulmonary stenosis with a systolic pressure gradient of $25 \mathrm{~mm}$. $\mathrm{Hg}$ or more. 


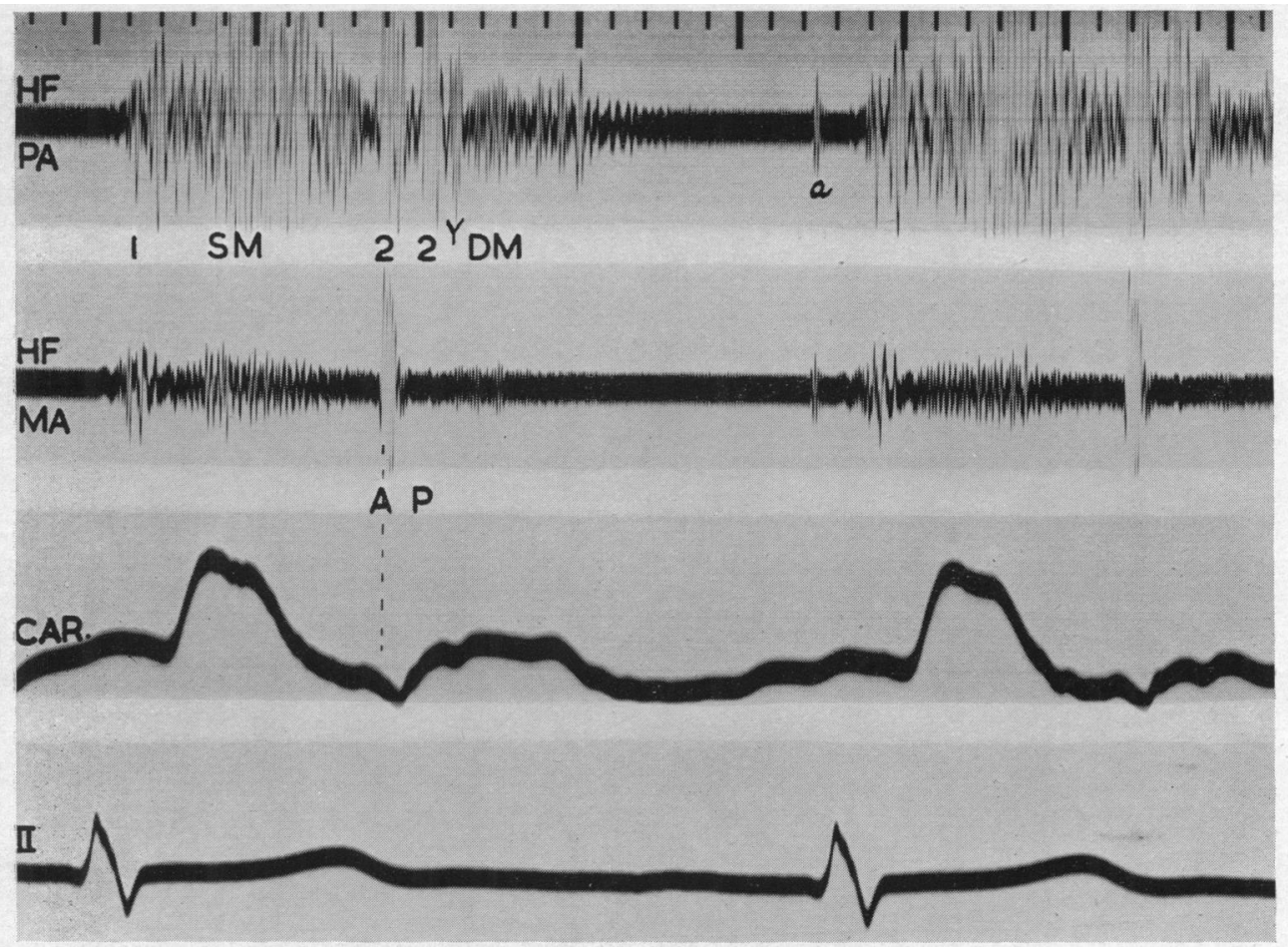

Fig. 9.-Atrial septal defect (pulmonary flow 10, systemic flow 7, 1./min.; PA P, $45 / 10 \mathrm{~mm}$. Hg). Transmission of pulmonary ejection systolic murmur to apex. Wide splitting of second sound, early diastolic sound, and delayed diastolic murmur. An artefact is marked " a ".

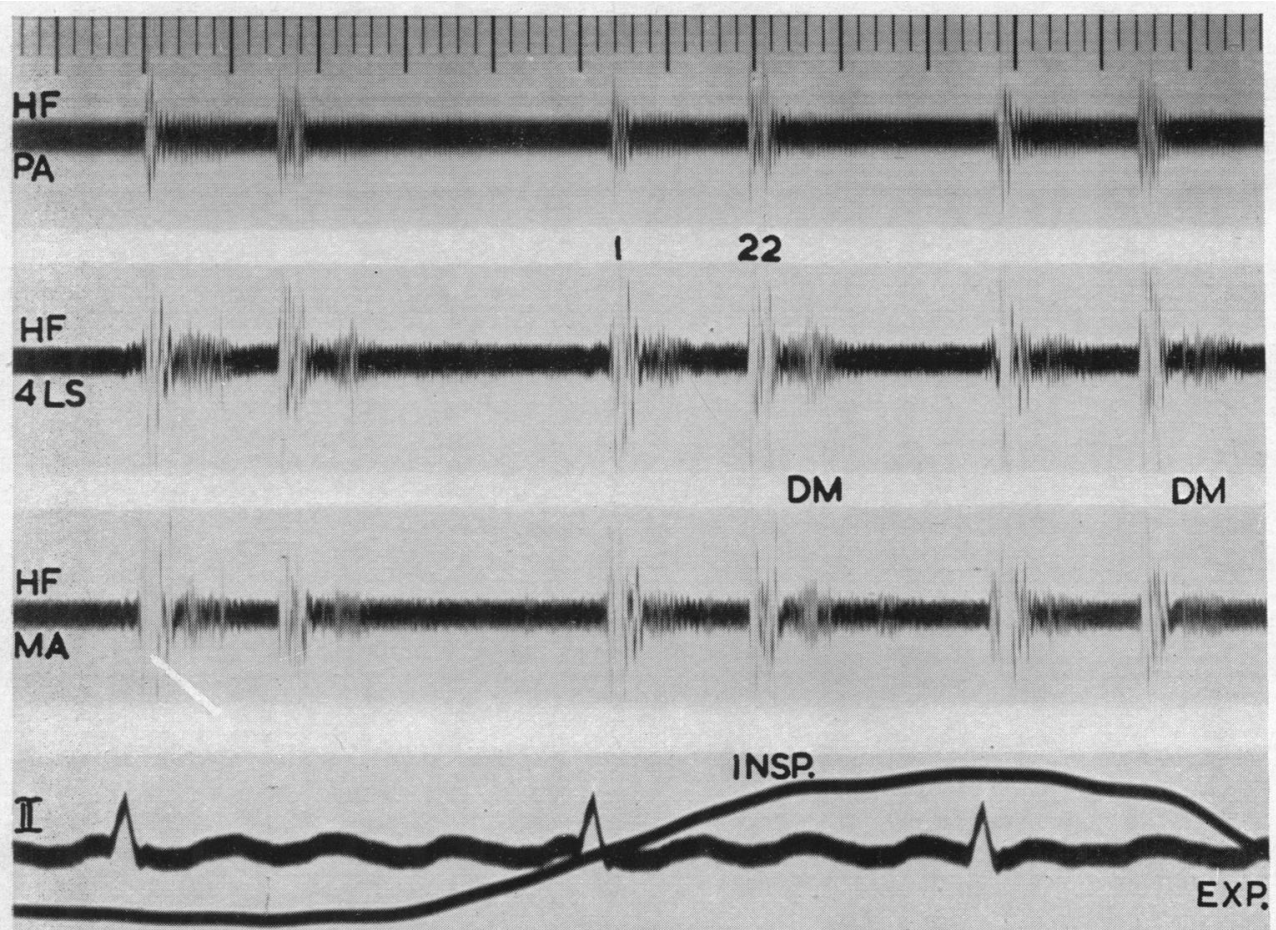

FIG. 10.-Atrial septal defect (pulmonary twice systemic flow). Delayed diastolic murmur at lower left sternal edge increasing on inspiration. 
In 5 of the 40 cases a pansystolic murmur was heard and recorded from the lower left sternal edge and mitral area (Fig. 3 and 7), and was invariably associated with gross pulmonary hypertension, and in two cases with signs of tricuspid incompetence.

Diastolic Murmurs. Diastolic murmurs were heard in 27 cases and in most of them could be recorded. They were of two types. (1) In 7 a long high-pitched early diastolic murmur was heard in the pulmonary area and was thought to be due to pulmonary incompetence (Fig. 3). All these patients had pulmonary hypertension, the lowest measuring $57 / 30 \mathrm{~mm}$. $\mathrm{Hg}$, with extreme enlargement of the pulmonary artery. (2) In 21 , there was a short delayed diastolic murmur maximal below the pulmonary area (Fig. 1, 7, 8, 9, and 10), often localized to the third and fourth left space or below, and near the left sternal edge. The pitch of the murmur was often considered

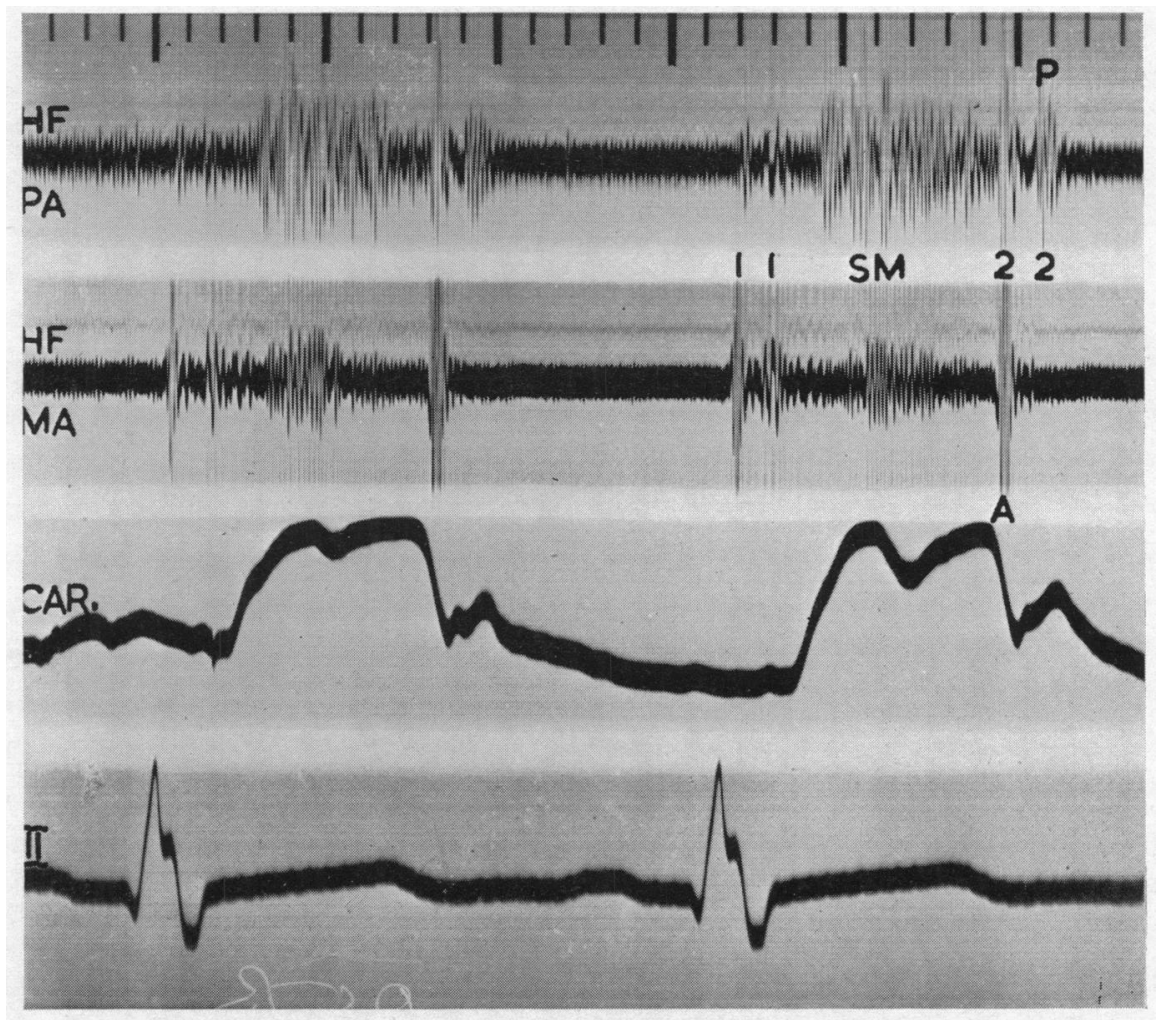

FIG. 11.-Atrial septal defect with complete right bundle-branch block. Wide splitting of first and second heart sounds.

to be intermediate between that of mitral and aortic diastolic murmurs, and the quality was frequently " scratching." Variation in intensity of the murmur was sometimes very striking, and a loud murmur might become inaudible and not able to be recorded at the next examination. There was an obvious increase in intensity of the murmur during inspiration (Fig. 10) and following exertion. In five patients the murmur followed immediately or shortly after an early diastolic sound. The delayed diastolic murmur began from 0.04 to $0.12 \mathrm{sec}$. after the onset of pulmonary valve closure, and in cases with simultaneous phonocardiograms and right auricular tracings its onset was shown to be 0.02 to $0.04 \mathrm{sec}$. after the peak of the $\mathrm{V}$ wave (Fig. 12). The duration of the murmur was short, varying from 0.04 to $0.20 \mathrm{sec}$.

An atrial systolic (presystolic) murmur was recorded from the apex and lower left sternal edge in 3 of our 40 patients (Fig. 1 and 13) and was of very low intensity being audible in only one. 


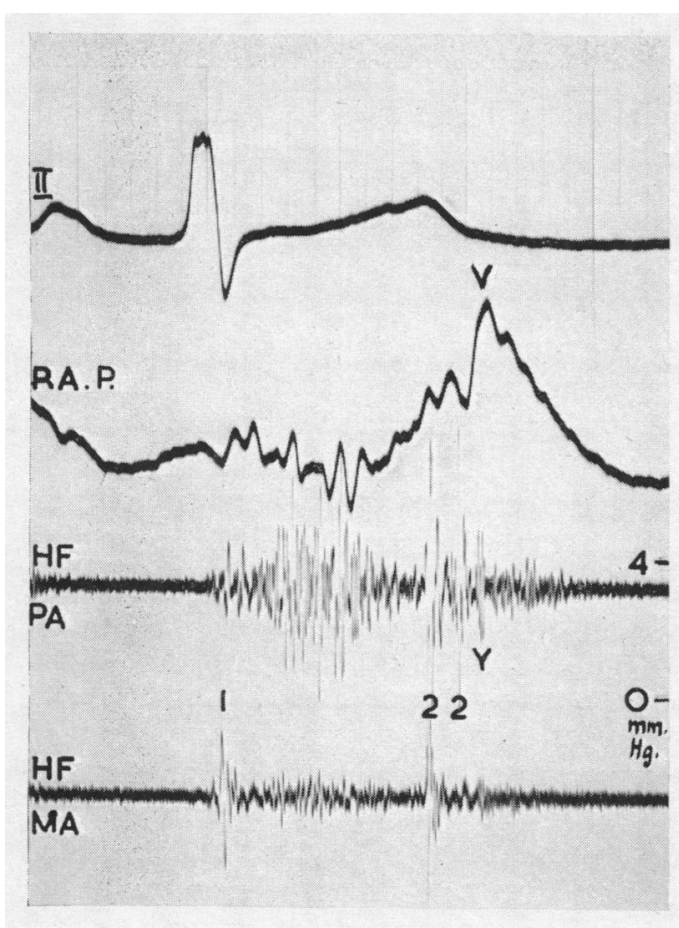

Fig. 12.-Atrial septal defect (same case as Fig. 9). Simultaneous right atrial pressure tracing (RA P) and phonocardiograms. The early diastolic sound and the onset of the delayed diastolic murmur coincide approximately with the peak of the $v$ wave.

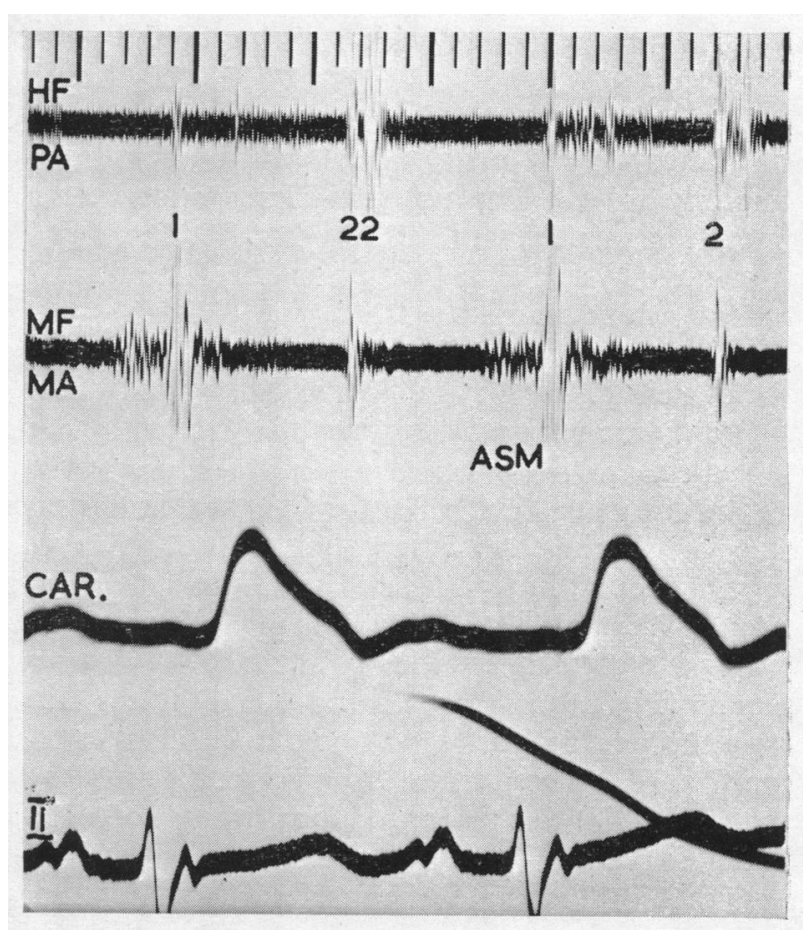

FIG. 13.-Atrial septal defect with mitral valve disease at operation. Atrial systolic vibrations begin $0 \cdot 12 \mathrm{sec}$. after the onset of the $\mathbf{P}$ wave suggesting a left atrial origin.

\section{Discussion}

The loud first sound in 17 patients might have been attributed to associated mitral stenosis. However, accentuation of mitral closure is not, perhaps, to be expected in mitral stenosis when there is an atrial septal defect with left-to-right shunt, as the left atrial pressure is not raised. Furthermore, added mitral stenosis was thought to be rare in our cases, as will be mentioned later, and was absent at operation in the patient with the loudest first sound that we have met. Accentuation of tricuspid valve closure was a more likely cause of the loud first sound. The increased tricuspid flow would be expected to keep the tricuspid valve open at the end of diastole causing a loud closing sound with the onset of ventricular contraction. A loud first sound was commoner in patients with high rates of flow (8 out of 13 with large shunts), but was also found in those with smaller flows ( 9 out of 27 with smaller shunts).

The pulmonary early systolic ejection sound and its association with enlargement of the pulmonary artery and pulmonary hypertension have been recently investigated (Leatham and Vogelpoel, 1954). It is a high-pitched sound in early systole, maximal in the pulmonary area and commonly increasing in intensity in expiration. Its location, timing, and quality can usually distinguish it from splitting of the first sound. It was recorded in 15 of our patients and was invariably associated with enlargement of the pulmonary artery. It was found in 7 of the 8 with extreme pulmonary arterial enlargement and in 8 of the 30 with slight or moderate enlargement. This sound was not confined to the patients with pulmonary hypertension though it was more frequent and more obvious in this group ( 8 out of 10 with pulmonary hypertension, and in 7 out of 30 with normal pulmonary pressures). 
The importance of wide splitting of the second heart sound as a sign of atrial septal defect was pointed out by Barber et al. (1950) and by Matthews (1949). The phonocardiogram shows that the characteristic abnormality in atrial septal defect is the wide splitting of the second sound in the expiratory phase of continued respiration, caused by relative delay in closure of the pulmonary valve. The usual inspiratory increase is diminished or absent (Towers (1950), whose attention was drawn to this by Mr. W. Dicks). The wide and constant splitting is a particularly obvious physical sign because of the diminution of the systolic murmur before both components of the second sound.

Barber et al. (1950) suggested that the relative delay in closure of the pulmonary valve might be due either to delay in electrical activation of the right ventricle from right bundle-branch block, or to mechanical prolongation of right ventricular systole owing to the selective increase in rightsided flow.

A delay in activation of the right ventricle is suggested by the term " partial right bundle-branch block" (Barker and Valencia, 1949) as applied to the rSR complex of less than 0.12 sec. so frequently found in right chest leads in patients with atrial septal defect (Routier et al., 1940; Barber et al., 1950). Right bundle-branch block of any degree would cause delay in closure of the tricuspid valve and abnormally wide splitting of the first sound corresponding to the splitting of the second sound (Fig. 11). This was found only in the six cases with complete right bundle-branch block, and the electrical delay was confirmed in the two in whom catheterization of both ventricles was performed. The interval from the onset of QRS to the upstroke of the right ventricular pressure pulse (Q-RV) was prolonged to an average of $0.10 \mathrm{sec}$. compared with an interval of $0.05 \mathrm{sec}$. for the left ventricle $(\mathrm{Q}-\mathrm{LV})$. In the remaining 34 the cardiogram showed an rSR complex measuring less than $0 \cdot 12$ sec., and the first heart sound was not abnormally split. Absence of electrical delay in eight of these cases where both ventricles were catheterized was confirmed by finding a Q-RV time of $0.05 \mathrm{sec}$., which is less than the average normal given by Coblentz et al. (1949), and a Q-LV time approximately the same. Furthermore the presence of an rSR complex in 11 subjects with either a healthy heart or rheumatic heart disease gave rise to no abnormal splitting of the second heart sound. Thus, the widely split second sound of atrial septal defect cannot be explained by delay in electrical activation of the right ventricle in the majority of cases.

Unequal duration of right and left ventricular systole might be expected from the greatly increased right-sided flow of atrial septal defect (average ratio pulmonary to systemic flow 2:3:1). The duration of right and left ventricular systole as measured from the phonocardiogram in 20 cases showed a constant prolongation of right over left of $0.02 \mathrm{sec}$., and this persisted throughout the respiratory cycle.

It is concluded that the difference between right- and left-sided flows causes relative prolongation of right ventricular systole and that this is the major factor causing the wide and constant splitting of the second sound in atrial septal defect. This conception is supported by observations on three patients in whom surgical closure of the septal defect restored normal splitting of the second heart sound without any change in the electrocardiogram. A similar mechanism is probably responsible for the phasic splitting of the second sound in normal subjects. The delay in closure of the pulmonary valve is then limited to inspiration when the negative intra-thoracic pressure causes increased filling of the right ventricle from its large extra-thoracic venous reservoir without a similar increase on the left side.

A moderately loud basal systolic murmur has generally been regarded as a frequent finding in atrial septal defect (Roesler, 1934; Bedford et al., 1941; Barber et al., 1950). A characteristic murmur that was maximal in the neighbourhood of the pulmonary area was recorded in 36 of our cases. The onset soon after the first sound, the crescendo in early or mid-systole and, most important, the cessation of the murmur before pulmonary valve closure, all suggest that this murmur is caused by the ejection of blood into the pulmonary artery. This is supported by the timing of the ejection sound, which, when present, immediately preceded the onset of the murmur (Leatham and Vogelpoel, 1954). The gap between the first sound and the onset of the murmur tended to 
be longer in the patients with pulmonary hypertension (bearing an approximate relation to the isometric time of the right ventricle).

All systolic murmurs caused by the ejection of blood through the aortic or pulmonary valve have approximately the same graphic configuration whether due to stenosis, valvular disease without stenosis, increased flow, or dilatation of the vessel beyond a normal valve. In atrial septal defect the systolic murmur seems related to the increased flow into the pulmonary artery rather than to dilatation of this, vessel. With added pulmonary hypertension and the greatest enlargement of the pulmonary artery, but with relatively normal flow, the murmur tended to be diminished or even absent. The most important graphic feature of the murmur is its cessation before the corresponding second sound, as would be expected since the flow is at that time much diminished. With added pulmonary stenosis the murmur tended to last longer because of the prolongation of right ventricular systole and the greater intensity of the murmur. In atrial septal defect there was frequent transmission of the ejection systolic murmur to the apex, even when this murmur was of slight intensity. This finding may be explained by the greatly dilated right ventricle forming the apex of the heart, and is comparable with the transmission of aortic systolic murmurs to the apex when this is formed by the left ventricle. The systolic murmur occasionally had the superficial scratching quality not uncommonly found in other pulmonary systolic murmurs in the absence of pulmonary stenosis.

In 5 patients quite a different systolic murmur was recorded. The murmur was pansystolic, its intensity being almost constant throughout systole extending up to the second sound. This suggested that it was due to regurgitation from ventricle to atrium where the pressure difference, and therefore flow, continues right up to and even beyond aortic and pulmonary valve closure. This murmur was equally loud at the tricuspid and mitral areas and it was difficult to decide its source. All 5 had extreme pulmonary hypertension and were therefore liable to a functional tricuspid incompetence. In two the venous pulse showed obvious systolic waves and in one of them the systolic murmur became louder during inspiration. It was difficult to exclude organic mitral incompetence as the cause of the murmur in the other three; indeed, one of them came to necropsy and had additional mitral valve disease.

The diastolic murmurs in patients with atrial septal defect have been attributed to pulmonary incompetence or to coincident mitral valve disease. A long high-pitched diastolic murmur beginning immediately after pulmonary valve closure, and maximal in the pulmonary area, was found in 7 of our patients and was invariably associated with great enlargement of the pulmonary artery and unmistakable signs of pulmonary hypertension. This murmur was attributed to pulmonary incompetence and resembled in every way the early diastolic murmur found in pulmonary hypertension from other causes.

A different short diastolic murmur was found in 21 of our patients and has been noted by Evans (1954), and Reinhold and Nadas (1954). It started appreciably later than pulmonary valve closure and corresponded with the period of rapid ventricular filling. There seem to be three possible causes for this murmur-coincident mitral valve disease, flow through the atrial septal defect, or increased flow through a normal tricuspid valve.

An abnormal mitral valve is frequently associated with atrial septal defect (41 of Roesler's (1934) cases and 8 of our 17 with necropsy or operative confirmation), although frank stenosis is much less common (Nadas and Alimurung, 1952), occurring in only 6 of Roesler's cases and 2 of ours. Associated mitral valve disease has usually been held responsible for the delayed diastolic murmur in atrial septal defect. The site, quality, and increase in intensity on inspiration all suggested that this diastolic murmur was not of mitral origin. It was therefore likely to be associated with the shunt through the atrial septal defect or the increased flow through the tricuspid valve. The presence of the diastolic murmur in only 2 of the 10 cases with pulmonary hypertension and reduced left-to-right shunt is in keeping with either of these two possibilities. Thus, the clinical evidence suggested that this diastolic murmur was not related to mitral valve disease. Wood (1955) mentions a case of atrial septal defect in which a loud delayed diastolic murmur with thrill 
led to the diagnosis of added mitral stenosis, but at operation the mitral valve was normal. We have heard and recorded loud delayed diastolic murmurs in three patients with atrial septal defect who had normal mitral valves at necropsy or operation, and there was no diastolic murmur in two others with atrial septal defect and appreciable mitral stenosis.

The location of the delayed diastolic murmur about the fourth intercostal space and near the -sternum would be consistent with its origin from flow through either the atrial septal defect or the tricuspid valve. The onset of the murmur corresponding with the descending limb of the right atrial $v$ wave (Fig. 12) showed that there was a relation to the phase of maximal flow through the tricuspid valve. At this point in the cardiac cycle pressure differences between the two atria are said to be minimal (Calazel et al., 1951; Schaffer et al., 1954) so that a surge of flow through the defect giving rise to a murmur would not be expected. An increase in intensity during inspiration is a known feature of tricuspid murmurs and is caused by the negative intra-thoracic pressure drawing blood from the extra-thoracic systemic venous reservoir. No increase in intensity on inspiration would be expected if the murmur arose at the atrial septal defect since both right and left atria and pulmonary veins are equally influenced by the change of intra-thoracic pressure. Thus, increased flow through the tricuspid valve seems the most likely cause of the delayed diastolic murmur of atrial septal defect. The murmur is comparable with the delayed diastolic murmur from increased left-sided flow through the mitral valve in patients with ventricular septal defect and patent ductus arteriosus (Wood, 1950).

The extra diastolic sound was seldom an obvious physical sign although in one patient it was loud and had been diagnosed as the opening snap of mitral stenosis: at operation the mitral valve was normal. The sound immediately preceded the diastolic murmur, when both were present, suggesting that it might be associated with opening of the tricuspid valve-a tricuspid snap. A simultaneous recording of the right atrial pressure pulse with phonocardiograms in one case supported this possibility since the peak of $v$ coincided with the extra sound (Fig. 12). The highpitched quality of the sound and its early timing made it unlikely to be a right ventricular third heart sound.

An atrial systolic murmur was relatively uncommon in our 40 cases, but had been found in 4 of the 10 that came to necropsy or operation; 2 of them had complicating mitral valve disease. The time interval between the onset of the $P$ wave and the atrial vibrations on the phonocardiogram was $0.09 \mathrm{sec}$. in the 2 uncomplicated cases, corresponding with the electro-mechanical interval for the right atrium measured by Coblentz et al. (1949). In the two patients with mitral valve disease this interval was longer, 0.12 and 0.13 sec., suggesting an origin from the left atrium, for this is known to contract later than the right (Fig. 13). A similar, though rather longer, time interval of $0.14-0.16 \mathrm{sec}$. was found in 10 cases of uncomplicated mitral stenosis. Thus, it seems that the earlier (right) atrial systolic murmur is tricuspid in origin like the delayed diastolic murmur. The later (left) atrial systolic murmur was associated with additional mitral valve disease in the only two cases in which it was found.

Added Pulmonary Stenosis, Pulmonary Hypertension, or Mitral Stenosis

The signs of atrial septal defect are modified by additional pulmonary stenosis and pulmonary hypertension. In 7 patients a systolic pressure gradient of $25-50 \mathrm{~mm}$. $\mathrm{Hg}$ across the pulmonary valve led to the diagnosis of additional pulmonary valve stenosis, but atrial septal defect was still regarded as the dominant abnormality. The pulmonary systolic murmur was loud and accompanied by a thrill in 4 of these 7 immediately suggesting the additional lesion, but these signs occasionally occurred in pure atrial septal defect ( 3 of 33 cases). In 5 of the 7, the systolic murmur was longer than is usual in pure atrial septal defect reflecting the relative prolongation of right ventricular systole and the increased intensity of the systolic vibrations. Delay in pulmonary valve closure greater than in pure atrial septal defect, causing a split second sound of $0.06 \mathrm{sec}$. or more, was found in 6 of the 7 cases. The relative intensity of the pulmonary component was generally, but not invariably, diminished. 
In 10 patients additional pulmonary hypertension was diagnosed, because the pulmonary artery systolic pressure exceeded $50 \mathrm{~mm}$. $\mathrm{Hg}$ and the pulmonary resistance was greater than normal. In 8 of these, there was evidence of some right-to-left shunt since the arterial oxygen saturation was less than 90 per cent (greater than 90 per cent in our uncomplicated cases of atrial septal defect), and of these cases 2 with extremely high pulmonary resistance ( 22 and 25 units) had obvious central cyanosis and clubbing, and were diagnosed as Eisenmenger's syndrome (Wood, 1950). Despite the pulmonary hypertension the usual left-to-right shunt (pulmonary flow twice or more systemic flow) was maintained in all but the Eisenmenger patients and two others in whom the pulmonary resistance was almost as high.

In 8 of our 10 cases a pulmonary early systolic ejection sound was recorded, and was audible in most of them, but this sound did not invariably indicate pulmonary hypertension because it was found in 5 of our 23 uncomplicated cases. The time interval between the onset of tricuspid valve closure and the ejection sound averaged $0.06 \mathrm{sec}$. in those with pulmonary hypertension, against $0.04 \mathrm{sec}$. in the others, from the slight prolongation of isometric time in hypertension (Wiggers, 1952).

The usual ejection systolic murmur was absent in 4 of the 10 cases with pulmonary hypertension reflecting the smaller pulmonary flow in this group. The pansystolic murmur (5 cases) that was attributed to tricuspid (or mitral) incompetence was confined to this group. The pulmonary component of the second sound was invariably increased in intensity and transmitted to the mitral area. A wide and fixed splitting of the second sound was heard in 8 cases while in 2 there was a loud single second sound: these were the 2 diagnosed as Eisenmenger's syndrome, and it was concluded that absence of splitting of the second sound in the cases with pulmonary hypertension indicated balancing or reversal of the shunt. The early diastolic murmur was common ( 7 of the 10 cases) and was confined to this group. The delayed diastolic murmur of increased tricuspid flow was found in only 2 of these cases.

The diagnosis of additional mitral stenosis in cases of atrial septal defect is well known to be difficult although the incidence of significant narrowing of the mitral valve is now thought to be low and was only present in 2 of our 17 cases that came to operation or necropsy. In the absence of increased left atrial pressure the characteristic auscultatory signs such as the loud first sound, opening snap, and mitral diastolic murmur, and the selective enlargement of the left atrium do not occur. In addition the delayed diastolic murmur of atrial septal defect creates further difficulty. Our findings suggest that a left atrial systolic murmur may sometimes be of value, but often, perhaps, in the majority, the mitral stenosis is silent.

\section{SUMMARY}

The auscultatory and phonocardiographic signs are described in 50 patients with atrial septal defect and they are attributed to the increased flow through the tricuspid and pulmonary valves from the left-to-right shunt. The increased tricuspid flow frequently gives rise to a loud first sound, a delayed diastolic murmur sometimes preceded by a small sound, and occasionally a right atrial systolic murmur. The increased pulmonary flow causes a mid-systolic ejection murmur and delay in closure of the pulmonary valve giving a wide and constant splitting of the second heart sound.

With added pulmonary hypertension there is usually a pulmonary early systolic ejection sound, accentuation of the pulmonary component of the second sound, and the early diastolic murmur of pulmonary incompetence. There may be a pansystolic murmur from added tricuspid incompetence. In the presence of a high pulmonary vascular resistance, and diminution and reversal of the shunt, the tricuspid diastolic murmur, the pulmonary systolic murmur, and the wide splitting of the second sound, tend to disappear.

When pulmonary stenosis is added the systolic murmur is louder and longer and pulmonary valve closure is more delayed.

Additional mitral stenosis is difficult to diagnose since the loud first sound and the delayed 
diastolic murmur preceded by an opening sound can occur in uncomplicated atrial septal defect, but it may be suspected if a left atrial systolic murmur is recorded.

The heart sounds and murmurs of atrial septal defect are shown by phonocardiography to be characteristic. They can usually be recognized by auscultation and should prove to be of help in the clinical diagnosis.

We wish to thank the physicians of the National Heart Hospital for allowing us to investigate and present their cases. We are also grateful to Dr. Paul Wood and Dr. William Evans for much helpful criticism. We are much indebted to the technical staff of the Institute of Cardiology for their assistance in making the recordings.

\section{REFERENCES}

Assmann, H. (1929). Die klinische Röntgendiagnostik der inneren Erkrankungen. 4th ed., Leipzig.

Barber, J. M., Magidson, O., and Wood, P. (1950). Brit. Heart J., 12, 277.

Barker, J. M., and Valencia, F. (1949). Amer. Heart J., 38, 376.

Bedford, D. E., Papp, C., and Parkinson, J. (1941). Brit. Heart J., 3, 37.

Brannon, E. S., Weens, H. S., and Warren, J. V. (1945). Amer. J. med. Sci., 210, 480.

Burrett, J. B., and White, P. D. (1945). Amer. J. med. Sci., 209, 355.

Calazel, P., Gerrard, R., Daley, R., Draper, A., Foster, J., and Bing, J. R. (1951). Johns Hopk. Hosp. Bull., 88, 20.

Coblentz, B., Harvey, R. M., Ferrer, M. I., Cournand, A., and Richard, D. W. (1949). Brit. Heart J., $11,1$.

Evans, W. (1954). Cardiography. 2nd ed., Butterworth, London.

Freeman, A. R., and Levine, S. A. (1933). Ann. intern. Med., 6, 1371.

Leatham, A. (1952). Brit. med. Bull., 8, 333.

(1954). Lancet, 2, 607.

- and Vogelpoel, L. (1954). Brit. Heart. J., 16, 21.

Matthews, M. B. (1949). St. Thom. Hosp. Rep., 5, 10.

Nadas, A. S., and Alimurung, M. M. (1952). Amer. Heart J., 43, 691.

Reinhold, J. D. L., and Nadas, A. S. (1954). Amer. Heart J., 47, 405.

Roesler, H. (1934). Arch. intern. Med., 54, 339.

Routier, D., Brumlik, J., and Malinsky, A. (1940). Arch. Mal. Coeur, 33, 40.

Shaffer, A. B., Silber, E. N., and Katz, L. N. (1954). Circulation, 10, 527.

Taussig, H. B., Harvey, A. M., and Follis, R. H. (1938). Johns Hopk. Hosp. Bull., 63, 61.

Towers, M. K. (1950). Personal communication.

Wiggers, C. J. (1952). Circulatory Dynamics. Gunn and Stratton, New York.

Wood, P. (1950). Brit. med. J. (ii), 639, 693.

- (1955). Personal communication. 